\title{
The effect of laser surface re-melting on the surface roughness and micro-hardness of selective laser melting (SLM) fabricated Ti-6Al-4V samples
}

\author{
G Molatlhegia, S Hoosain ${ }^{b}$, API Popoolab, N Malatjia, S Pityanab \\ ${ }^{a}$ Department of Chemical, Metallurgical and Materials Engineering, Tshwane University of Technology, Pretoria, 0183, South Africa \\ ${ }^{b}$ National Laser Center, Council for Scientific and Industrial Research, Meiring Naude' Road, Brummeria, Pretoria 0185, South Africa
}

\begin{abstract}
Ti-6Al-4V is favourable due to its exquisite properties for example, low modulus, light weight, excellent strength, and corrosion resistance. Despite the excellent properties of the material, the fabrication process of titanium components is challenging due to the poor final surface quality components caused by non-uniform powder distribution during additive manufacturing (AM) using selective laser melting (SLM) process. SLM process produces fully denser parts with better mechanical properties compared to the bulk materials, although the surface quality is poor. This work aims to study the effect of laser surface re-melting (LSM) on the hardness and surface properties of Ti-6Al-4V alloy. The fabricated Ti-6Al-4V sheet was re-melted by a $3 \mathrm{~kW}$ IPG Fiber laser. Microstructural evaluations of the Ti-6Al-4V sheet were characterized using an optical microscope. Micro-hardness and surface roughness measurements were determined by means of an HV Vickers tester under an applied load of 300g and load time of 10s and MarSurf PS1 roughness tester machine respectively. Microstructural evolution and hardness properties were all examined before and after the LSM treatment. The experimental results showed the formation of martensitic structure on the areas treated. Micro-hardness depth profiling results showed an average increase of $15-25 \%$ which was higher compared to the average hardness of the as-received. The results indicated that the roughness measurements lowered when both the residence time and irradiance increase. Laser surface re-melting treatment showed an improvement of the microstructural modifications and hardness properties therefore, the process can be used to modify the component's surface for reliable and best surface finish.
\end{abstract}

Keywords: Ti-6Al-4V, SLM, Laser Re-melting, Micro-hardness, Roughness

\section{Introduction}

Nowadays the demand to manufacture components with good mechanical performance and good surface finish are of great necessity in the aerospace industries (Hassanin et al. (2018); Iwaszko and Strzelecka (2016)). The selective laser melting (SLM) process is one of the well-known, commonly used additive manufacturing (SLM) technologies. The process offers the ability to produce parts with desired geometrical shapes, without tools, reduced costs, material usage and component weight. The process is used to fabricate metal components for various industries such as the medical, aerospace, automotive and chemical industries.

Through the selective laser melting fabrication process, powders are melted with heat from a laser power beam. When heat is applied on the powder material, powders melts and forms a melt pool (Song et al. (2012); Chikarakara et al. (2012); Casalino et al (2015); Gong et al. (2017)). Then the formation of parts occurs when the molten pool solidifies. Partial melting of the powder staircasing leads to the formation of different microstructures and poor surface quality for aerospace applications respectively. Nicoletto et al. (2018) stated that poor surface quality of parts is one key factor that causes component failures during applications and reduces the component's life span.

In addition, SLM as-built components are exposed to high temperatures which causes powder particles to get attached to molten surface during the process. This will trigger the surface roughness of components. High surface roughness affects components negatively in a way that it lowers mechanical performance in areas that requires high strength, in highly stressed and cyclically loaded areas. According to the study by Vaithilingam et al. (2016), surface roughness (Ra) value of $17.6 \mu \mathrm{m}$ for Ti-6Al$4 \mathrm{~V}$ parts was produced via Renishaw's AM 250 SLM machine. According to the study conducted by Yue et al. (2002) and Balla et al. (2014), optimization of SLM parameters such as hatch distance, spacing, particle size and feed powder can also improve surface quality to some degree.

Therefore, to improve surface quality of SLM fabricated parts, numerous post-processing techniques including sandblasting, machining, etching, electro polishing and plasma spraying, are employed Bagehorn et al. (2017) . One limitation of using the above-mentioned techniques is the amount of time needed to treat parts with complex shapes. Bagehorn et al. (2017) stated that any opportunity for improved SLM surface quality is of great importance to enable direct fabrication of various parts without the need for post-treatments. Song et al. (2012); Hassanin et al. (2018); Tian et al.(2005); Lwaszko et al. (2016) further proposed laser surface re-melting technique as one of the outstanding post processing techniques with the potential to improve Titanium and Titanium alloy surface quality of SLM parts. Therefore, to enhance surface quality of SLM Ti-6Al-4V parts, laser re-melting was used 

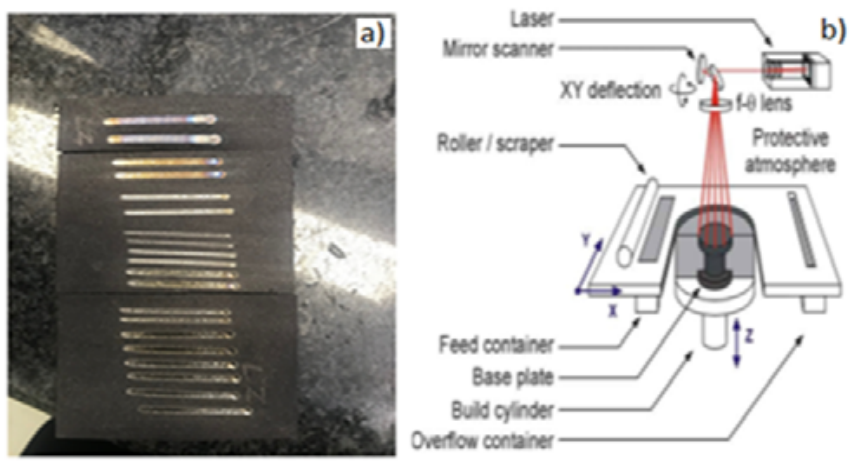

Figure 1: a) Test parts built by SLM and exposed to laser surface re-melting, b) Operating principle of SLM process Kruth et al. (2010)

with the aim to reduce the roughness and improve hardness of the components like laser surface polishing.

The results from the work done by Song et al. (2012); Hassanin et al. (2018); Tian et al.(2005); Lwaszko et al. (2016) proved that the laser treated parts did reduce the surface roughness of the materials and also used enhanced both mechanical performance and microhardness of the materials. The current study is mainly focused on the effect of laser re-melting on the surface roughness and microhardness of SLM produced Ti-6Al-4V.

\section{Material and Methods}

The Ti-6Al-4V (120mm by $60 \mathrm{~mm}$ ) sheet alloy for this experiment was manufactured by SLM process. The Ti-6Al-4V sheet was fabricated by IPG fiber laser source characterized by a $3 \mathrm{~mm}$ spot diameter and a maximum output power of $1000 \mathrm{~W}$. The laser sinters the powder together, layer-by-layer until the model is completed. After the sheets were manufactured the specimens were taken for re-melting as part of the post treatment for reduced surface roughness of the as built and determine the best optimum

Table 1: Laser Re-melting with varied Laser Scanning Speed

\begin{tabular}{ccc}
\hline Spot Size $[\mathbf{m m}]$ & Power $[\mathbf{W}]$ & Speed $[\mathbf{m} / \mathbf{m i n}]$ \\
\hline 3 & 750 & 0.5 \\
3 & 750 & 1 \\
3 & 750 & 1.5 \\
3 & 750 & 2 \\
3 & 750 & 2.5 \\
\hline
\end{tabular}

parameters (laser power and scanning speed) to ensure uniform smooth surface finishing. Prior to all analysis the, the samples were taken for metallographic preparation. For the microstructural analysis, the sections were cut, polished, and etched using kroll solution for $15 \mathrm{~s}$ and were subsequently analysed using Olympus light optical microscope equipped with Analysis ${ }^{\circledR}$ software. Micro-hardness tests were performed on the cross sections using a Vickers micro-hardness testing system under $300 \mathrm{~g}$ load for 10 s dwell time and linked to an image processing system for capturing microstructures. Five measurements were averaged for each depth. The objective of the micro-hardness tests was to analyse the hardness variances along the diverse microstructural zones caused by the heat transferred by the laser beam speed. The surface roughness measurements were done using the MarSurf PS1 roughness tester machine. In this paper, the arithmetic mean surface roughness $\left(\mathrm{R}_{\mathrm{a}}\right)$ is used to represent the roughness.

All the specimens were manufactured on a SLM machine. The following parameters were used for laser treatment:

Table 2: Laser Re-melting with varied Laser Power

\begin{tabular}{ccc}
\hline Spot Size $[\mathbf{m m}]$ & Power $[\mathbf{W}]$ & Speed $[\mathbf{m} / \mathbf{m i n}]$ \\
\hline 3 & 750 & 1 \\
3 & 500 & 1 \\
3 & 450 & 1 \\
3 & 350 & 1 \\
3 & 250 & 1 \\
\hline
\end{tabular}

\section{Results and discussions}

The microstructural characterizations were done after the LSR and the samples were prepared and etched in kroll for $15 \mathrm{~s}$ and were later analyzed with Olympus light optical microscope equipped with Analysis ${ }^{\circledR}$ software. Ti-6Al-4V samples are characterized by the alpha and beta phase structures where the dark sections are known as the beta and the lighter sections, the alpha phase. According to (Kolli and Devaraj (2018)), the alpha grain structure is classified with hard particle properties as compared to the beta grain structure. Fig. 2 Shows the present phases on re-melted Ti$6 \mathrm{Al}-4 \mathrm{~V}$ alloy at $109 \mu \mathrm{m}$ magnification.

Figure $2 \mathrm{a}$ and $2 \mathrm{~b}$ shows the image of initial Ti-6Al-4V prior LSR and after. Laser surface re-melting traces cross section in Fig. $2 \mathrm{~b}$, divided into three zones: The substrate, re-melted zone, and heat affected zone. The remelted zone shows microstructures
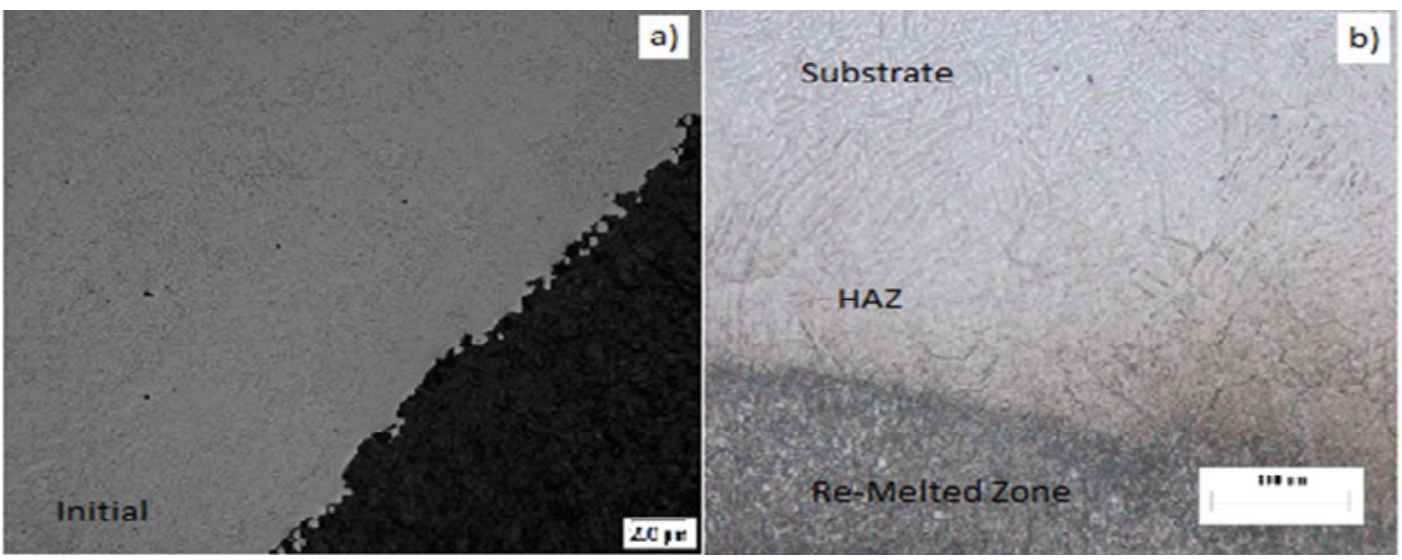

Figure 2: Re-melting trace cross section microstructure after LSR 


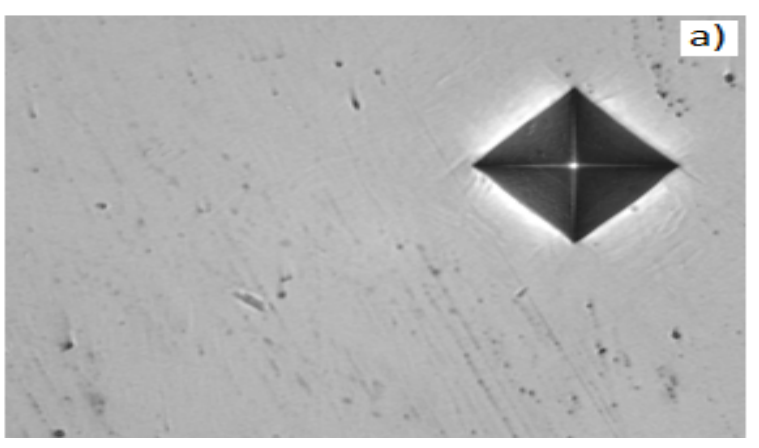

Figure 3: Micro-hardness indentation of the as-built

Micro-hardness at varied scanning speed

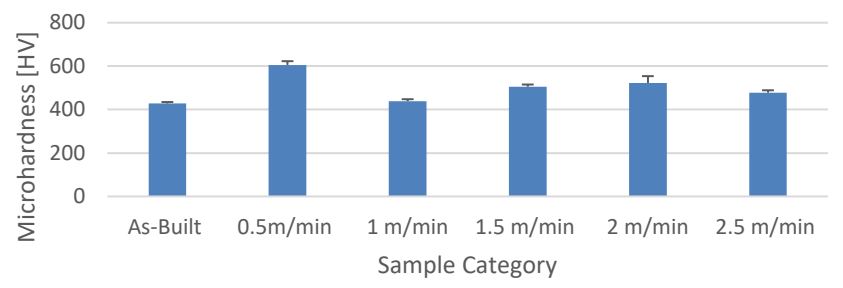

Figure 4: Micro-hardness test measures at different laser scanning speed

with dark spots caused by high energy input during melting, The heat affected zone (HAZ) it is the non-melted part of the material that experienced changes in its material properties as a results of exposure to high heat. The three regions were difficult to appear simultaneously under the same light due to the presence of both the $\alpha$ and $\beta$ phase. As a results of high temperature gradients during LSR, the articular and fine martensite $\alpha$ phase is observed.

\subsection{Micro-hardness profiling}

The microhardness profiles were done on the laser re-melted Ti$6 \mathrm{Al}-4 \mathrm{~V}$ sheet. The tests were performed on the cross sections using a Vickers micro-hardness testing system under a $300 \mathrm{~g}$ load for $10 \mathrm{~s}$ dwell time and linked to an image processing system for capturing microstructures. Five indentations were done on each sample to allow accurate measurements. Fig 3 below shows the microhardness indentation of the as-built.

An 349_5230.5m/min resulted in the highest hardness value of 600 $\mathrm{HV}$, which means that the longer the residence time resulted in the most improvement.

According to studies by Vamsi et al. (2014) and Yao et al. (2014) the high micro-hardness measurements for re-melted materials are triggered by the development of acicular $\alpha$ and reduction in amount of $\beta$ phase in these materials. The variation of laser power had enormous influence on the hardness. Based on the results above Figure 5, it is evident that the hardness increases when the laser power increases. Hardness results obtained at laser power of $250 \mathrm{~W}$ drastically decreased, this is due to the lower melting temperatures applied. The hardness is directly related with heating and cooling of the melt pool, at these low laser powers, it is apparent that the transformation temperatures are not attained.

It is evident that high laser power outputs enhance the microhardness properties of the re-melted samples. Nevertheless, the

\section{Micro-hardness at varied laser power}

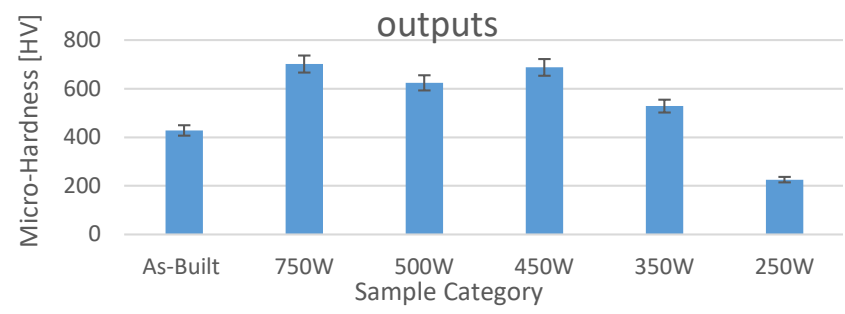

Figure 5: Micro-hardness test measures at different laser power outputs

\section{Arithmetic Mean Roughness Ra}

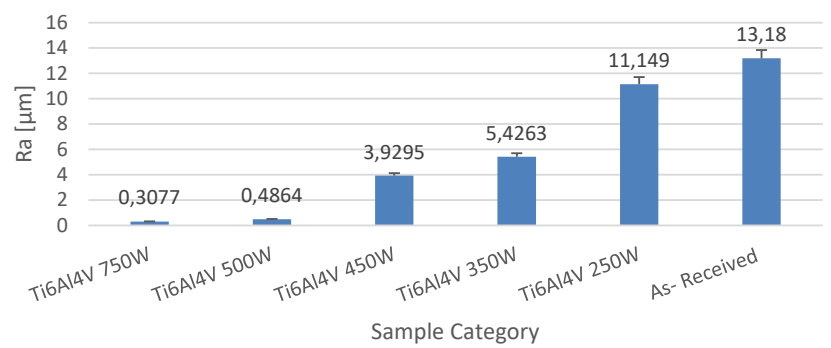

Figure 6: Average $\mathrm{R}_{\mathrm{a}}$ and Standard Deviation of Laser Re-melted samples for varied Laser Power Outputs

optimum laser power input ranges between $750 \mathrm{~W}$ and $450 \mathrm{~W}$. It was proven that the hardness of the specimen in the re-melted zone increased significantly as the laser power increased and it slightly increase as the scanning velocity increases. The found regularities should be linked with the cooling rate of the material resulting from the applied treatment parameters, and in consequence, with the extent of the obtained refinement of structure. The samples were left to cool at room temperature.

\subsection{Roughness}

The LSR samples showed an improvement on the roughness values as compared to the as built. However, the laser surface remelting depends highly on laser power and scan speed. Based on the results obtained, low power results in high surface roughness values. Roughness average ( $\mathrm{Ra}$ ) obtained for lower power of $250 \mathrm{~W}$ averaged between $10.81 \mu \mathrm{m}$ and $11.49 \mu \mathrm{m}$ showing no improvement on the specimen. The roughness was not reduced because of lower laser power. Further homogenous melting on the specimens attributed to the decrease in the roughness thus producing smoother surfaces. Increased laser power output exhibited improvement on the specimen surface roughness.

The surface roughness of the as-built showed high initial surface roughness after SLM. Roughness of the re-melted specimen reduced when the laser power increased. Visible significant changes revealed that proper melting of the materials allows smooth surface and with no defects. Reduced scanning velocity increases material contact time with the laser, which allows slow cooling rate and decreases roughness. Visible significant changes on sample surfaces treated with lasers at a power of $750 \mathrm{~W}$, confirm the occurrence of a large amount of discontinuities. 


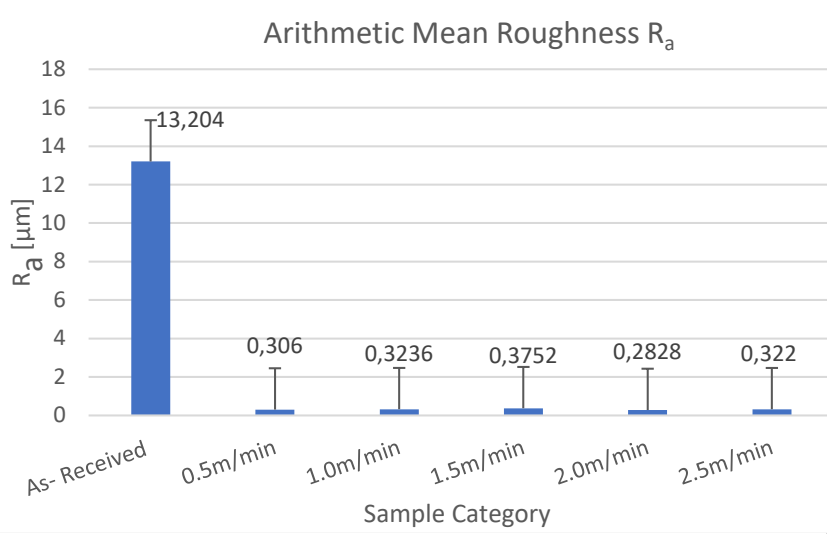

Figure 7: Average Ra and Standard Deviation of Laser Re-melted samples for varied Laser Scanning Speed

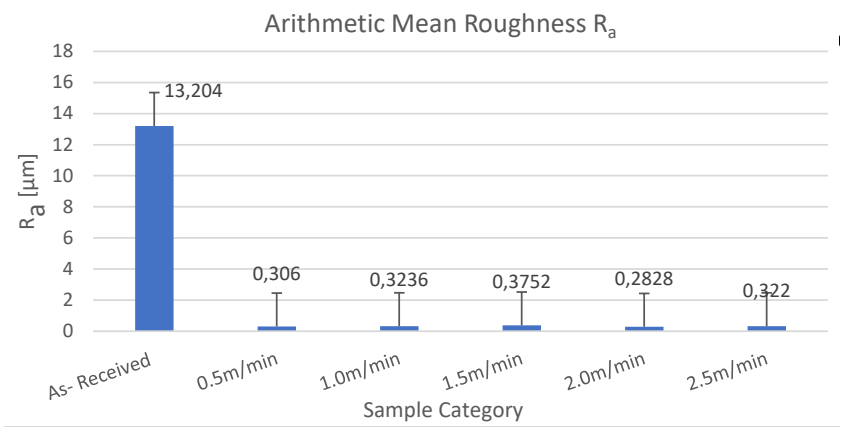

Figure 8: Average $\mathrm{R}_{\mathrm{a}}$ and Standard Deviation of Laser Re-melted samples for varied Laser Scanning Speed

In order to get a smother surface, a liquid state (thin layer) must be attained, this means the process parameters must be able to melt the Ti64.

\section{Conclusions}

Laser surface re-melting attested to be one of the effective surface finishing method for Ti-6Al-4V alloy. With optimized process parameters such as laser power and scanning speed, laser surface re-melting technique will lead to enhanced surface roughness and improvement on the mechanical performances of the alloy. The study revealed that as the laser scanning speed drops, both the hardness and roughness of the samples increases. It can be said that the optimum laser power ranged between $500 \mathrm{~W}$ and $350 \mathrm{~W}$ and optimum scanning speed between $0.5 \mathrm{~m} / \mathrm{min}$ and $2 \mathrm{~m} / \mathrm{min}$ respectively for the improved hardness properties. Using the above-mentioned parameters guarantees a crack free surface sample. For improved surface roughness the optimum parameters are concluded as follows: $750 \mathrm{~W}$ power outputs at laser speed of $2 \mathrm{~m} / \mathrm{min}$.

\section{Acknowledgements}

The work done in this research paper is supported by the CSIR and Tshwane University of Technology.

\section{References}

1. Józef Iwaszko, Monika Strzelecka. Effect of cw-CO2 laser surface treatment on structure and properties of AZ91 magnesium alloy, Optics and Lasers in Engineering, 81(2016) 63-69.

2. Bo Song, Shujuan Dong, Hanlin Liao \& Christian Coddet. Process parameter selection for selective laser melting of ti6al4v based on temperature distribution simulation and experimental sintering. The international journal of advanced manufacturing technology, 61,(2012) 967-974.

3. Evans Chikarakara, Sumsun Naher, Dermot Brabazon. High speed laser surface modification of ti-6al-4v. Surface \& coatings technology 206;(2012) 3223-3229.

4. G. Casalino, S.L. Campanelli, N. Contuzzi, A.D. Ludovico. Experimental investigation and statistical optimisation of the selective laser melting process of a maraging steel, Optics \& Laser Technology, 65(2015)151-158.

5. Haijun Gong, J S Dilip, Li Yang, Chong Teng, Brent Stucker. Influence of small particles inclusion on selective laser melting of Ti-6Al-4V powder, IOP Conference Series: Materials Science and Engineering, 2017,25-27.

6. Hany Hassanin, Amr Elshaer, Redha Benhadj- Djilali, Francesco Modica, Irene Fassi. Chapter 7 Surface Finish Improvement of Additive Manufactured Metal Parts, Springer Nature, 2018,145-164.

7. Jayasheelan Vaithilingam, Ruth D. Goodridge, Richard J.M. Hague, Steven D.R. Christie, Steve Edmondson. The effect of laser remelting on the surface chemistry of ti6al4v components fabricated by selective laser melting. Journal of materials processing technology. 2321(2016)8

8. Nicoletto G, Konečná R, Frkáň, E.M. Riva. Surface roughness and directional fatigue behavior of as-built ebm and dmls ti6al4v. International journal of fatigue 116;(2018) 140-148.

9. S. Bagehorn, J. Wehr, H.J. Maier. Application of mechanical surface finishing processes for roughness reduction and fatigue improvement of additively manufactured Ti-6Al-4V parts, International Journal of Fatigue, 102(2017)135-142

10. Vamsi Krishna Balla, Julie Soderlind, Susmita Bose, Amit Bandyopadhyay. Microstructure, mechanical and wear properties of laser surface melted Ti6A14V alloy, Journal of the Mechanical Behavior of Biomedical Materials, 32 (2014) 335-344.

11. Vamsi Krishna Balla, Julie Soderlind, Susmita Bose, Amit Bandyopadhyay. Microstructure, mechanical and wear properties of laser surface melted ti6al4v alloy, journal of the mechanical behavior of biomedical materials. 2014

12. Y. Yao, X. Li, Y.Y. Wang, W. Zhao, G. Li, R.P. Liu. Microstructural evolution and mechanical properties of Ti-Zr beta titanium alloy after laser surface remelting, Journal of Alloys and Compounds, 583 (2014) 43-47.

13. Y.S.Tian, C.Z.Chen, S.T.Li, Q.H.Huo, Research progress on laser surface modification of titanium alloys. Applied surface science. 242(2005)177-184. 